VATSAL RAKESH SINGHANIA, B.Eng. ${ }^{1}$

E-mail: vatsal.singhania@gmail.com

MARIN MARINOV, Ph.D. ${ }^{1}$

E-mail: marin.marinov@ncl.ac.uk

${ }^{1}$ School of Mechanical and Systems Engineering

Newcastle University

Claremond Road, Stephenson Building

Newcastle upon Tyne, NE1 7RU, UK
Transport Technology

Preliminary Communication

Submitted: 8 Nov. 2016

Accepted: 6 July 2017

\title{
AN EVENT-BASED SIMULATION MODEL FOR ANALYSING THE UTILIZATION LEVELS OF A RAILWAY LINE IN URBAN AREA
}

\begin{abstract}
This paper offers a simulation model for analysing the utilization levels of a section of a railway line between Edinburgh Waverley and Glasgow Queen Street. Specifically, a segment of this line situated in the urban area of Edinburgh has been simulated using SIMUL8 to study the impacts of further inclusion of freight trains on the scheduled passenger trains. The utilisation levels of this segment have been observed in three scenarios: utilisation existing state where all scheduled passenger trains and a few freight trains are observed; utilisation in future state where more freight trains are input in available time gaps running at their actual speed; and utilisation future state where freight trains are input in available time gaps running at speed equivalent to a passenger train. A decomposition approach is implemented. The results suggest that extra freight trains can be input into the current timetables without impeding the current scenario, allowing a reasonable increase in utilisation of the rail line.
\end{abstract}

\section{KEY WORDS}

rail line; rail freight; passenger trains; freight trains; urban area; simulation; utilisation;

\section{INTRODUCTION}

Freight trains often provide a feasible economic option to transport bulk goods such as coal to power stations, or commodities to manufacturing plants across the country as compared to traditional road transport. A quarter of the electricity used to power UK is transported by rail. However, road transport still has the upper hand when it comes to short-haul distances and is preferred for door-to-door delivery due to the immense networking offered by roads. Freight flow for intermodal goods is on the rise and a subsequent result of this is expected, suggesting a growth of rail freight use by an astounding 30\% [1].

This presents an interesting challenge and opportunity for the rail network operations department. To incorporate the growing demand for freight trains, various aspects of the industry such as infrastructure, speed limits, passenger priority, signalling capabilities etc. need to be addressed in the near future. There are also other social causes implied by running freight trains at night that must be considered with the noise and vibrations generated by these freight trains.

This task falls within the vast subject of operating capacity of rail networks and notes. Railway network capacity expansion models have been developed in [2] to ease tactical planning of rail activities and so decide on how and where to expand a rail network in the study. Infrastructure occupation and capacity consumption including delay have been studied in [3]. A model has been developed to evaluate the impact of increase in the number of trains and advise if the robustness of the whole system has been improved when juggling different "infrastructure" scenarios. Analytical and probabilistic models have been used to study the "carrying" capacity of complex rail nodes. Nodes normally represent rail stations and techniques sourced from Probability Theory are implemented to study train movement in rail stations [4].

The aim of this study is to identify if there is potential for adding more freight trains to the existing schedule and incorporate a simulation work using SIMUL8 in addressing key aspects of improved freight train capacity in a railway line dominated by passenger trains. Interested readers are also referred to [5], where the question of adding extra freight trains in a railway network has also been discussed.

The range of this study is to recreate the Edinburgh Waverley - Glasgow Queen Street line in detail with help of SIMUL8 and to identify the utilisation of individual segments along the way, keeping in mind the impact it may have on the existing passenger trains.

The freight flow from Edinburgh Waverley - Glasgow Queen Street is used for simulation modelling purposes to indicate possible effects of growing freight train services in a passenger train dominated line. Simulation 
modelling is ideal to recreate different scenarios on the same line and help identify improvements for the existing situation.

Data acquisition is a significant part of the study as there is a strict schedule maintained by ScotRail to ensure smooth flow of traffic along the Edinburgh Waverley - Glasgow Queen Street Line. Following the data acquisition an analysis is carried out to identify potential gaps in the system where freight trains can be fed. These gaps are identified based on the restrictions this line offers for freight and/or passenger trains in terms of electrification, speed, passing loops, signalling capabilities, gauge allowances, and the like.

Once the data set is analysed, the simulation is transformed to emulate the existing line in the truest way possible and results are acquired. The results are further analysed and recommendations are proposed to provide insight on the progression of the subject. The proposed recommendations are based on the results for possible freight growth along this line.

A decomposition approach is undertaken to study the train movement of this line [6]. This approach involves breaking up the system into different segments for research purposes, $[7,8]$. While using the method of decomposition it is crucial to maintain continuity within the system to extract an accurate analysis from the model. Provided the integrity of the system is maintained, the network can be divided into its components [9].

The trains travel only in a single direction unless intercepted with yards, terminals or sidings. Busy rail networks for long paths use single track for one direction.

\section{TECHNICAL CHARACTERISTICS OF RAIL LINE}

There are a total of four routes connecting East of Scotland to its central region. Two routes connect Edinburgh Waverley and Glasgow Central; the other two connect Edinburgh Waverley and Glasgow Queen Street. A shuttle runs between the two Glasgow stations every 30 minutes making it convenient for the passengers and freight to travel southward. The Bathgate - Airdrie line was re-opened to improve the frequency of passenger trains between Edinburgh Waverley and Glasgow Queen Street. The primary passenger route among the four paths is the Edinburgh-Falkirk High - Glasgow Queen Street line. For the purposes of this study, the primary passenger route has been chosen.

The Edinburgh Waverley - Falkirk High - Glasgow Queen Street line is only electrified for a certain path (Edinburgh Waverley to Newbridge Junction) using AC.

Although the line speed for this path (Edinburgh - Falkirk High - Glasgow Queen Street) is between
$130 \mathrm{~km} / \mathrm{h}$ [80 mph] to $160 \mathrm{~km} / \mathrm{h}$ [a100 mph], freight trains are restricted to travel at $120 \mathrm{~km} / \mathrm{h}$ [75 mph].

Although the maximum allowable speed per freight train is set to be $120 \mathrm{~km} / \mathrm{h}$ [75 mph], most trains on the average do not make it close to this speed due to various speed restrictions along the way set by tunnels, junctions etc. [10]. Acceleration time of freight trains is also significantly higher than of normal passenger trains due to the excess weight.

The Edinburgh Waverley - Falkirk High - Glasgow Queen Street line incorporates a 3-aspect signal system. Each signal-to-signal section is deemed as a block. The lengths of these blocks are determined by the stopping speed of trains and are usually $1.6 \mathrm{~km}$ [1 mile]. Effectively this is used to avoid collisions and if there is a train in the $3^{\text {rd }}$ block the subsequent train is stopped at the beginning of the $1^{\text {st }}$ block. However, if there is no train in the $3^{\text {rd }}$ block then the green signal allows the train in the first block to go through without any impeding consequences.

For the railway line on the whole there is a double track (one upwards, one downwards), but as we look at the movement of trains in one direction, from Edinburgh Waverley to Glasgow Queen Street via Haymarket, the rail operation in place is studied as a single track line. There are multiple junctions along the way that allow trains to come into the system or go out of it, as shown in Figure 1.

The management of trains is by blocks (also called block sections). One block is every $3.2 \mathrm{~km}$ [two miles]. This is based on the signalling pattern used along this line and means that only one train can enter a single block, which is in conformity with the 3-aspect signalling rules, thereby not allowing any other train to enter when one block is used.

This study is focused on the analysis of train movement between Edinburgh Waverly and Haymarket. This section is characterized with a mixed traffic operating at high density and also appears to be one of the bottlenecks along the line under study.

\section{SIMULATION MODELLING}

Computer simulations are regularly used to evaluate the system performance and capacity when changes in existing schedules are introduced. Simulation models help analyse the impacts of these changes [6, $7,11,12,13]$. The capacity of a system is defined as its ability to move a certain amount of traffic before reaching saturation with minimal influence to the other parameters of the system. For the purpose of this study an event-based simulation software, SIMUL8, is used. Specifically, SIMUL8 is an event-based software for dynamics visualization of a process flow. It has the ability to model detailed networks and evaluate them over time to calculate utilisation factors and identify gaps in the system [14]. It is traditionally used for 


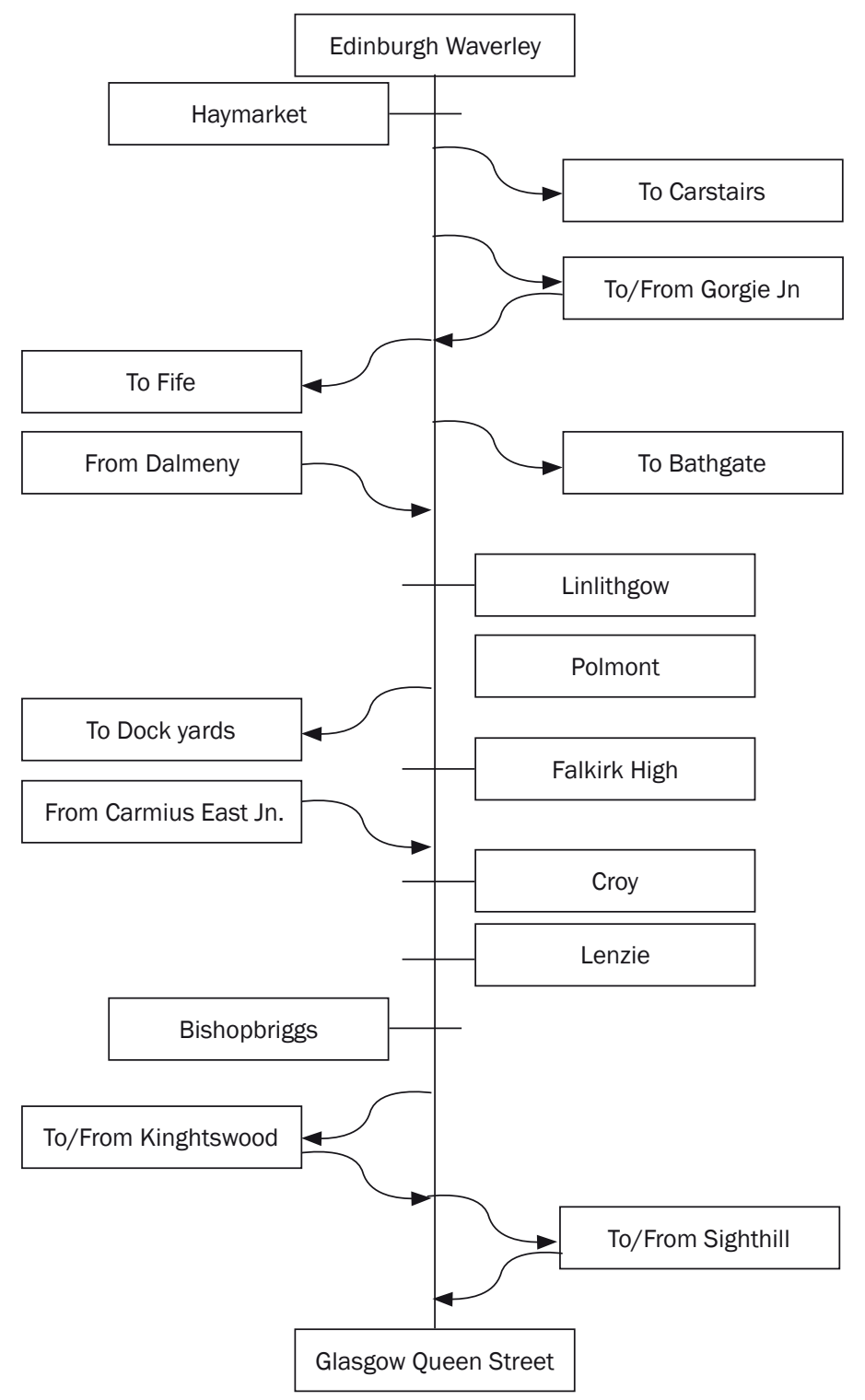

Figure 1 - Graphical represenation of the junctions along the rail line in study

production plants but can be customised for other process flows that follow a similar pattern. It is chosen for this study because of its capacity to produce detailed process flow and logically pattern the network. Previous applications for studying rail-based systems using SIMUL8 include for instance [15] and [16]. SIMUL8 attributes:

Start Time - SIMUL8 allows the user to define the time parameters and units of the simulations thereby allowing each model to be run a specific number of hours in a specific week recursively. This model is set to run for 7 hours from 5:00 am to allow the system to incorporate all the trains in the schedule. The units chosen are seconds since there are travel times in the system which requires that degree of precision. Simul 8 works on the basis of nodes and arcs where the nodes characterise the server or work centres and the arcs represent the connection between these servers. The nodes represent the stations, junctions and block sections whereas the arcs represent the single track line or connection between the nodes.

Generator - There are work entry points (or start points as denoted on the software), where the work items are input into the system, essentially the passenger and freight trains. In this case they follow a strict schedule and a schedule sheet replicates the collected data. The train times can be in multiple formats; for this purpose the time is input exactly at departure time into the schedule sheet.

Work Centres - These represent the stations and junctions that have influence on the work items (essentially "clients") of the system. This has also been used to model the block sessions of the rail line since it can display utilisation levels. All the operations run 
on these work items are controlled from Work Centres' panels; these include the routing in, the routing out, wait time, etc. The options for the type of distribution, the actions to be conducted on the work items and the routing facilities allow the user to replicate the real world scenario as accurately as possible. The work leaving the activity is generally routed out to other work centres, queues or end points.

Queues or Buffers - They are elements in the simulation that act as storage areas in production facilities, but in this model they are used to accommodate multiple trains in the same line.

Work Flow Arrows - These represent the direction of flow of the work items in the system. Since the model is using a single track from Edinburgh Waverley to Glasgow Queen Street all the arrows replicate the flow path of the trains and have their heading towards Glasgow Queen Street.
Transient period - An initial transient period is set up by SIMUL8 (default); this causes the system to have an induced bias and can hamper the results. To evade this bias a warm-up time is set and the results are collected without alterations. The warm-up time in a model is dependent on the simulation requirements and the actual time varies from model to model. It only needs to be set up once at the beginning of the simulation.

Iterations - the benefit of using a simulation method over an analytical one is the extended number of run times that simulation software can offer over the traditional method. This is used widely to give a realistic view of the situation with the random variable changing every run and returning collective results. The aim is to see the utilisation of lines of the system in the current state and future state (with freight trains).

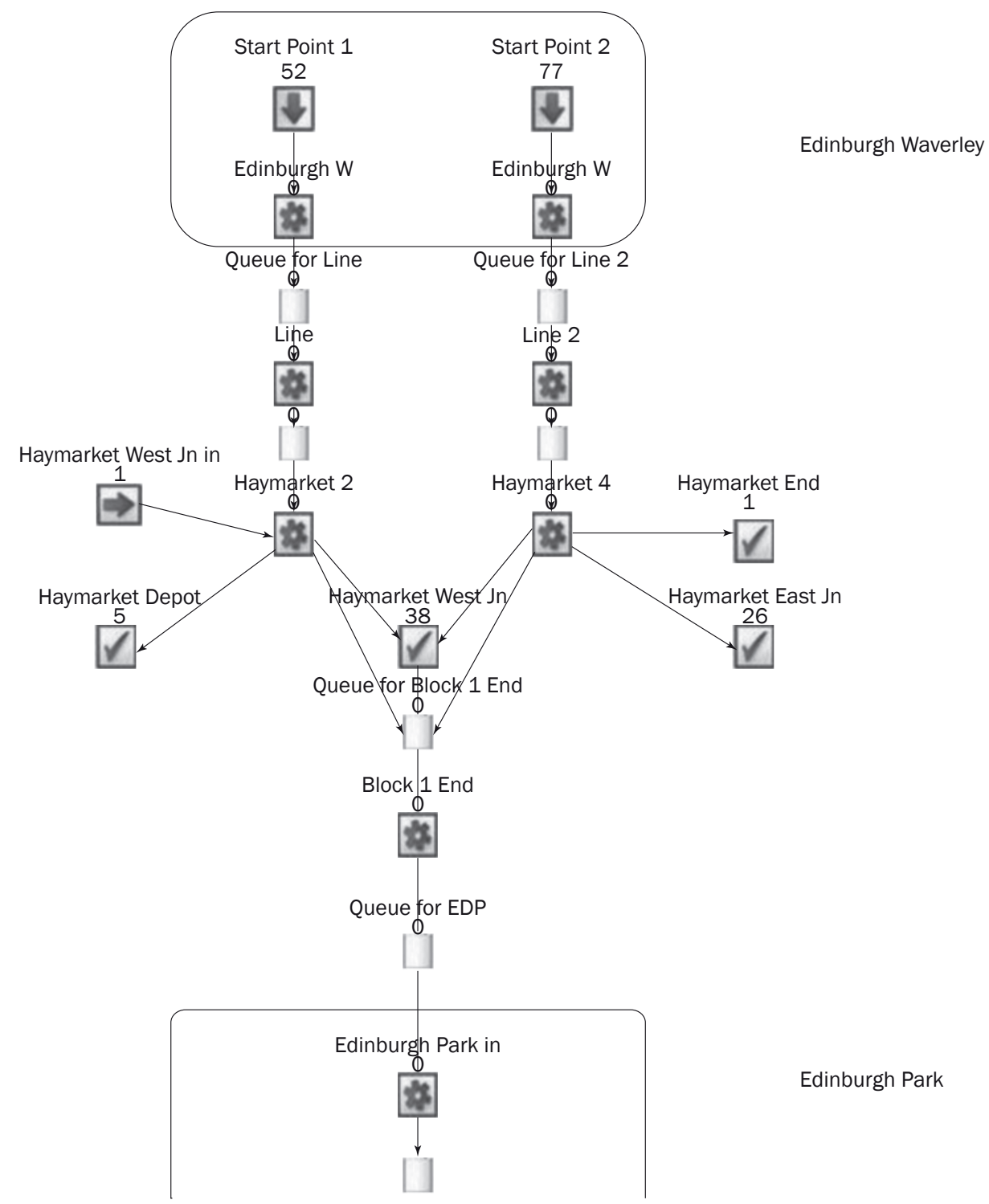

Figure 2 - A screenshot representing a part of the rail network in SIMUL8 environment 
Visual logic - To incorporate the different trains that leave the system (at specific junctions), a set of visual logic commands are set so that the trains are completely out of the system (or reach an end point) and do not hamper the remaining trains. Visual logic is also set to indicate different travel times of freight trains and passenger trains. This is necessary so the results are calculated from the same activity without having to make a new activity with different travel times. Visual presentation of the simulation model for the selected section of the study is shown in Figure 2.

Block System - Each block section is modelled as an activity to allow the capacity of one train to stay in at a time. An example of arrival patterns used by the model, indicating the generation of trains at Edinburgh Waverly and Haymarket West Junction over a period of time, is shown in Table 1.

Table 1 - An example of two arrival patterns, showing a generation of trains over time period

\begin{tabular}{||c|c|c||}
\hline Time & $\begin{array}{c}\text { Edinburgh } \\
\text { Waverly }\end{array}$ & $\begin{array}{c}\text { Haymarket West } \\
\text { Junction }\end{array}$ \\
\hline \hline $05: 21: 00$ & 1 & 1 \\
\hline $05: 30: 00$ & 1 & 1 \\
\hline $05: 38: 00$ & 1 & 1 \\
\hline $05: 52: 00$ & 1 & 1 \\
\hline $05: 56: 00$ & 1 & 1 \\
\hline $06: 16: 00$ & 1 & 1 \\
\hline $06: 21: 00$ & 1 & 1 \\
\hline $06: 33: 00$ & 1 & 1 \\
\hline $06: 37: 00$ & 1 & 1 \\
\hline $06: 48: 00$ & 1 & 1 \\
\hline $07: 00: 00$ & 1 & 1 \\
\hline $07: 03: 00$ & 1 & 1 \\
\hline $07: 07: 00$ & 1 & 1 \\
\hline $07: 10: 00$ & 1 & 1 \\
\hline $07: 17: 00$ & 1 & 1 \\
\hline $07: 21: 00$ & 1 & 1 \\
\hline $07: 28: 00$ & 1 & 1 \\
\hline $07: 33: 00$ & 1 & 1 \\
\hline $07: 38: 00$ & 1 & 1 \\
\hline $08: 00: 00$ & 1 & 1 \\
\hline $08: 07: 00$ & 1 & 1 \\
\hline $08: 10: 00$ & 1 & 1 \\
\hline
\end{tabular}

To build the model we used the schedule produced and published by ScotRail, which is an alliance employing around 7,500 people, delivering 2,200 services daily and carrying 93 million passengers annually. To validate the model against real time performance we used the data set maintained by Real Time Trains, which is an online platform providing timetables and real-time information for the movement of every single train in the British rail network. It was absolutely essential to build an accurate simulation model using exact departure times of all the scheduled regular trains. We also wanted to know more about the punctuality and deviations from strict fixed schedule, if any. Therefore, interim input-output results from the simulation models have been cross-checked against the schedule available by ScotRail and the information about real time performance of trains as it has been shown by Real Time Trains. Model validation was completed when the information of all three sources was deemed to be accurate after the cross-checks.

\section{GENERATION OF SCENARIOS}

The 5:00am - noon time-period has been chosen for the purposes of this discussion. The 6:00am -9:00am interval is considered peak hour for the service in this area, employing a tighter schedule. 9:00am onwards is considered off-peak hour. There are some freight trains set in to run at 5:00am providing service before the number of passenger trains significantly increases. It is now useful to analyse the number of trains that can be added to the system without hampering the current schedule and the existing conditions in critical sections along the line. These critical sections include very dense lines operating mixed traffic, serving large cities. Hence, we focus on the study of train movement from Edinburgh Waverley to Haymarket. Three scenarios have been generated:

Scenario 1: The current scenario, where the current number of passenger trains is four per hour from end to end with stops at different stations for each train, whereas the number of freight trains is merely three per day and they only use selective parts of the system. The headway is usually given in minutes and for this specific section the headway is 4 minutes. This means the minimum time before another train can leave a station is 4 minutes.

Scenario 2: If more freight trains are incorporated at their current speed, then the time taken by a freight train as per Real Time Trains is found to be 1.5 times the time taken by a passenger train for the same distance. For instance, the time taken by a passenger train from Edinburgh Waverley to Haymarket is four minutes whereas the time taken by a freight train to travel the same segment is six minutes. In the data file, gaps which allow a six minute travel time after a passenger train has departed from Edinburgh Waverley and reached Haymarket are identified. Subsequently, a separate generator is used to add these trains to the system. These freight trains are again added using a schedule sheet so as not to hamper with the model. The freight trains input into the system for the two lines are as follows:

- two trains added to the 'Start Point 1' line; 
- three trains added to the 'Start Point 2' line.

Scenario 3: If freight trains are incorporated into the system with the same travel time as passenger trains. This is a future state scenario which analyses the opportunities available if the freight trains are to run at passenger train speed. The allowable freight trains that can be put into the system for the slots are: - seven trains added to the 'Start Point 1' line;

- four trains added to the 'Start Point 2' line.

For the purposes of the analysis it is of importance to understand the behaviour of the system as described by Measures of System Performance (MoPs), namely; numbers of trains served (or completed jobs), number of trains in the system (or number of work items), of time trains awaiting work, actually working, blocked, stopped, etc.

Results obtained for Percent of time Working and Awaiting Work for all 3 Scenarios are presented in Figures 3 and 4.

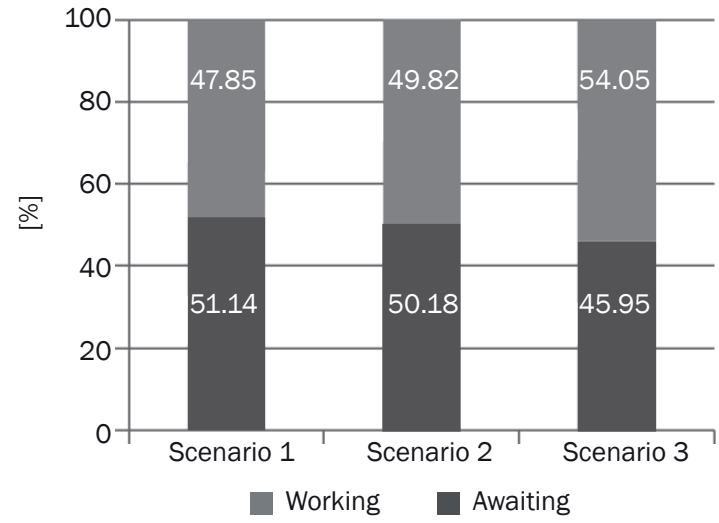

Figure 3 - Scenarios 1-3: Awaiting vs Working between Edinburgh Waverly and Haymarket platform 2

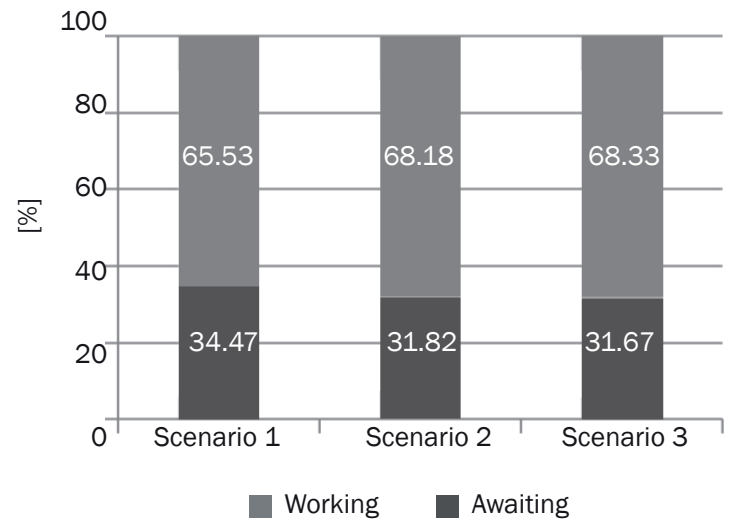

Figure 4 - Scenarios 1-3: Awaiting vs Working between Edinburgh Waverly and Haymarket platform 4

In Scenario 1 replicating the current situation, not a huge difference between the estimates of Percent of time Working and Awaiting Work is observed between Edinburgh Waverly and Haymarket platfrom 2 /platform 4 . With regard to Scenario 2 , more freight trains are now input into the system. The freight trains run at their scheduled speed taking more time than the passenger trains. As for Scenario 3, now all freight trains input into the system run at the same speed as passenger trains, meaning the travel time of every train is the same regardless of the type of service.

\section{RESULTS}

In Scenario 1 the utilisation for 'Start Point 1' line is $47.85 \%$, for 'Start Point 2 ' line it is $65.52 \%$. This scenario provides a base comparative utilisation factor for the succeeding scenarios. These utilisation factors indicate the amount of time these lines have been occupied in a period of 7 hours. The difference in utilisation factors between the two lines can be attributed to the difference in frequency of train flow between them. 'Start Point 2' line has a much higher frequency and hence is utilised significantly more.

In Scenario 2 the utilisation is increased for both; 'Start Point 1' line increases to $49.81 \%$ and 'Start Point 2' line goes up to $68.18 \%$. Table 2 indicates the number of added trains in all three scenarios and Figures 5 and 6 show the number of trains served for all 3 scenarios, Edinburgh Waverly and Haymarket platfrom 2/platform 4; since freight trains occupy the line for a longer period of time due to lower commuting speed then the utilisation increases. It has a negative impact on the productivity levels though.

Table 2 - Indicates the freight trains added to the system across the three scenarios

\begin{tabular}{||c|c|c||}
\hline \hline & $\begin{array}{c}\text { Number of Freight } \\
\text { trains input in Start } \\
\text { Point 1 line }\end{array}$ & $\begin{array}{c}\text { Number of Freight } \\
\text { trains input in Start } \\
\text { Point 2 line }\end{array}$ \\
\hline Scenario 1 & NA & NA \\
\hline Scenario 2 & 2 & 3 \\
\hline Scenario 3 & 7 & 4 \\
\hline
\end{tabular}

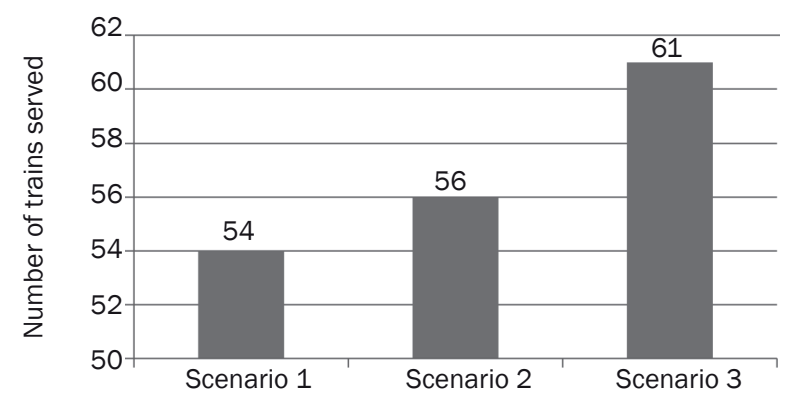

Figure 5 - Number of trains served, Edinburgh Waverly Haymarket platform 2

For Scenario 3 the freight trains are set to travel at the same speed as passenger trains, and the study showed that more freight trains can be added along the 'Start Point 1' line than its counterpart, which will result in a rise of line utilisation (up to 54.04\%). Spe- 
cifically, the increase in freight trains from Scenario 2 to Scenario 3 sees 'Start Point 1' line accommodating 5 more freight trains, whereas 'Start Point 2' line can only accommodate one more freight train from its previous scenario. Hence, recalling the most favourable Scenario 2, the total number of freight trains that can be added to the section in the study without altering any current situation is five.

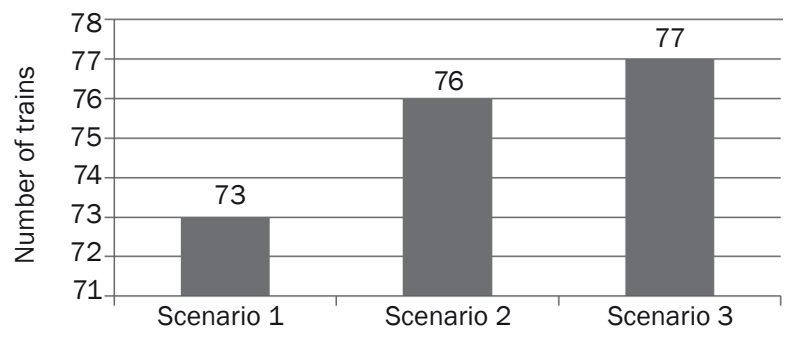

Figure 6 - Number of trains served, Edinburgh Waverly Haymarket platform 4

Figure 7 indicates the increase in utilisation of 'Start Point 1' line. If the speed of the freight trains is kept as it is and input into the system at the identified gaps, 2 more freight trains can be added in the slot of 7 hours. If the freight trains run at the same speed as passenger trains, the number of freight trains that can be added goes up to 7 more trains in the span of 7 hours. This indicates the wide possibility that exists in improving the utilisation of the railway line in the study. Any other added freight trains would hamper

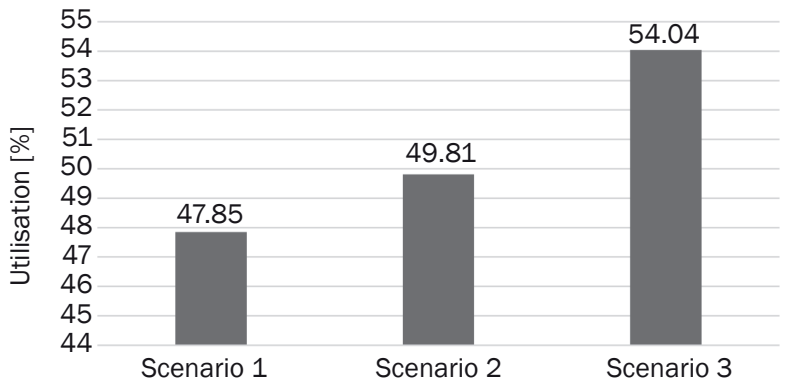

Figure 7 - Start Point 1 line from Edinburgh Waverley to Haymarket Platform 2: Utilisation in \% for Scenarios 1, 2 and 3

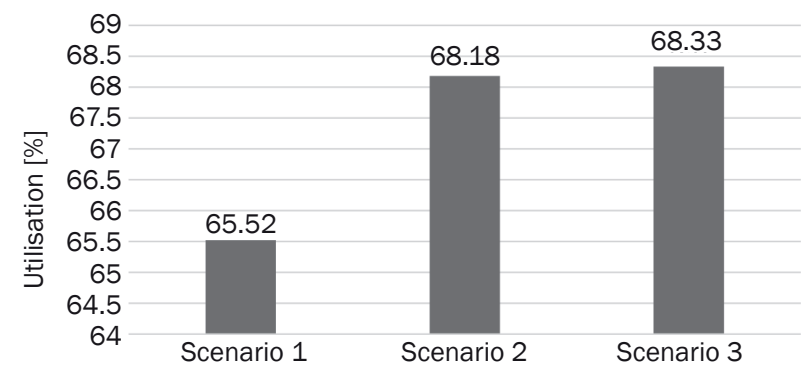

Figure 8 -Start Point 2 line from Edinburgh Waverley to Haymarket Platform 4: Utilisation in \% for Scenarios 1, 2 and 3 the currently scheduled passenger service and cause blockade. Figure 8 indicates the rise in utilisation for Start Point 2. From Scenario 1 to Scenario 2 there are 3 freight trains added to the system. This line is highly passenger dominated with a very high utilisation already but it can still accommodate 3 more freight trains without repercussions.

\section{CONCLUSIONS AND FUTURE WORK}

An even-based simulation model has been developed and implemented using SIMUL8 to study the utilisation levels of a segment of a railway line in Scotland. Specifically the line in study is situated in the urban area of Edinburgh (i.e. Edinburgh Waverly - Haymarket). By merely identifying potential gaps in the current schedule and inputting freight trains to run when following different speed patterns, it is concluded that more freight trains can be added in addition to the currently scheduled passenger trains. This suggests that there is potential for an increase of line utilisation without introducing changes in the current schedule. Specifically, the results of our simulation model showed that the total number of additional freight trains that can be added to the railway line under study without altering the current situation is five.

Future work will include a more detailed study on the behaviour of passenger trains to better understand the time-gap in which freight trains can be introduced but still without changing the current number of passenger trains, which is four per hour on average. The simulation model will be extended to cover more segments of the railway line in study. A cost-benefit analysis will be conducted to gain an understanding of the economic impacts on the line and the network from the inclusion of more freight trains into the current schedule. Further potential for the rail freight services along the line in study will be examined to understand if there is a possibility for multi-modal operations and if some of the freight services delivered by road can potentially be shifted to rail.

\section{REFERENCES}

[1] NetworkRail. Value and Importance of Rail Freight. Kings Place, 90 York Way, London N1 9AG; April 2013.

[2] Burdett, Robert L. Optimisation Models for Expanding a Railway's Theoretical Capacity. European Journal of Operational Research. 2016;3(251): 783-797.

[3] Jensen LW, Landex A, Nielsen OA, Kroon LG, Schmidt M. Strategic Assessment of Capacity Consumption in Railway Networks: Framework and model. Transportation Research Part C: Emerging Technologies. 2017;74: 126-149.

[4] Malavasi G, Molková T, Ricci S, Rotoli F. A Synthetic Approach to the Evaluation of the Carrying Capacity of Complex Railway Nodes. Journal of Rail Transport Planning \& Management. 2014;1(4): 28-42.

[5] Meirich C, Nießen N. Calculating the Maximal 
Number of Additional Freight Trains in a Railway Network. Journal of Rail Transport Planning \& Management. 2016;6(3): 200-217.

[6] Dessouky M, Leachman R. A Simulation Modeling Methodology for Analyzing Large Complex Rail Networks. Simulation. 1995;65(2):131-142.

[7] Marinov M, Viegas J. A Mesoscopic Simulation Modelling Methodology for Analyzing and Evaluating Freight Train Operations in a Rail Network. Simulation Modelling Practice and Theory. 2011;19: 516-539.

[8] Motraghi A, Marinov M. Analysis of Urban Freight by Rail Using Event Based Simulation. Simulation Modelling Practice and Theory. 2012;25: 73-89.

[9] Pachl J. Railway Operation and Control. VTD Rail Publishing; 2002.

[10] Marinov M, Mortimer P, Zunder T, Islam D. Short Haul Rail Freight Services. RELIT - Revista de Literatura dos Transportes. 2011;5(1): 136-153.

[11] Kavicka A, Klima V. Simulation Support for Railway Infrastructure Design and Planning Processes. In: Proceedings of COMPRAIL 2000 conference, Bologna, Italy. Southampton: Wessex Institute of Technol-
ogy-Computational Mechanics Publications; 2000. p. 447-456.

[12] Klima V, Kavicka A, Adamko N. Software Tool VirtuOS - Simulation of Railway Station Operation. In: $15^{\text {th }} \mathrm{Eu}$ ropean Simulation Multiconference, 6-9 June 2001, Prague: ESM.

[13] Klima V, Kavicka A. Virtual Railway Marshalling Yard. IFAC Proceedings Volumes. 1997;30(8): 843-846.

[14] Concannon KH, Hunter KI, Tremble JM. Simul8-Planner Simulation-based Planning and Scheduling. In: Proceedings of the 2003 Winter Simulation Conference, 7-10 Dec 2003, New Orleans, LA; 2003. p. 1488-1493.

[15] Marinov M, Viegas J. Analysis and Evaluation of Double Ended Flat-shunted Yard Performance Employing Two Yard Crews. Journal of Transportation Engineering. 2011;137(5): 319-326.

[16] Wales J, Marinov M. Analysis of Delays and Delay Mitigation on a Metropolitan Railway Network Using Event Based Simulation. Simulation Modelling Practice and Theory. 2015;52: 55-77. 